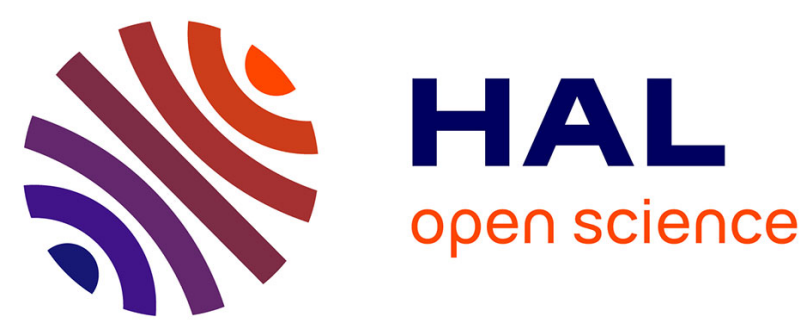

\title{
High-Grade Anal Intraepithelial Neoplasia: Progression to Invasive Cancer Is Not a Certainty
}

Mathilde Gautier, Charlène Brochard, Annie Lion, Sébastien Hénno, Anne

Laure Mallet, Anaïs Bodere, Guillaume Bouguen, Astrid Lièvre, Laurent

Siproudhis

\section{To cite this version:}

Mathilde Gautier, Charlène Brochard, Annie Lion, Sébastien Hénno, Anne Laure Mallet, et al.. HighGrade Anal Intraepithelial Neoplasia: Progression to Invasive Cancer Is Not a Certainty. Digestive and Liver Disease, 2016, 48 (7), pp.806-811. 10.1016/j.dld.2016.03.011 . hal-01295666

\section{HAL Id: hal-01295666 \\ https://hal-univ-rennes1.archives-ouvertes.fr/hal-01295666}

Submitted on 9 Jun 2016

HAL is a multi-disciplinary open access archive for the deposit and dissemination of scientific research documents, whether they are published or not. The documents may come from teaching and research institutions in France or abroad, or from public or private research centers.
L'archive ouverte pluridisciplinaire HAL, est destinée au dépôt et à la diffusion de documents scientifiques de niveau recherche, publiés ou non, émanant des établissements d'enseignement et de recherche français ou étrangers, des laboratoires publics ou privés. 


\title{
High-Grade Anal Intraepithelial Neoplasia: Progression to Invasive Cancer Is Not a Certainty
}

\author{
Mathilde Gautier(MD) ${ }^{1}$, Charlène Brochard(MD) ${ }^{123}$, Annie Lion(MD) ${ }^{1}$, Sébastien \\ Henno(MD) ${ }^{3}$, Anne Laure Mallet ${ }^{1}$, Anaïs Bodere(MD) ${ }^{1}$, Guillaume \\ Bouguen(MD,PhD $)^{123}$, Astrid Lièvre(MD,PhD) ${ }^{1}$, Laurent Siproudhis $(\mathrm{MD}, \mathrm{PhD})^{12^{3}}$ \\ ${ }^{1}$ Department of Hepato-Gastroenterology, University Hospital of Rennes, Pontchaillou, France \\ 2 INSERM U991, University of Rennes 1, Rennes, France \\ ${ }^{3} \mathrm{CIC}-1414$ University Hospital of Rennes, Pontchaillou, France \\ ${ }^{4}$ Department of Pathology, University Hospital of Rennes, Pontchaillou, France
}

Conflict of interest statement: None

Key words: anal cancer; high-grade intraepithelial neoplasia; human papillomavirus; regression; healing; smoking; sexual life; MSM; HIV, condylomas; age; cancer

Word count: 3473 
Background: The incidences of high-grade anal intraepithelial neoplasia (HSIL) and superficially invasive squamous cell carcinomas (SISCCA) related to human papillomavirus (HPV) have increased. These lesions can progress to invasive anal cancer. The aim of the study was to assess the clinical outcome with a special focus on the healing rate.

Methods: Forty-six consecutive patients (M/F:35/11; HIV+:30) with histologically proven HSIL lesions ( $N=41$ ) or SISCCA ( $N=5$ ) were enrolled in a follow-up survey.

Results: Of the 46 patients, 40 were treated by excision $(n=9)$, electrocoagulation $(n=13)$, topical treatment $(n=2)$ or combined strategies $(n=16)$. After a mean follow-up of 35 (27-43) months, only one patient progressed to an invasive cancer. Regression and healing were observed in $14(30 \%)$ and $15(33 \%)$ patients. The cumulative probabilities of healing were $14 \%$, $49 \%$ and $74 \%$ after 1,3 and 5 years. None of the current smokers healed. Heterosexual patients, sexual abstinence, patients older than 44 years old, non-smokers, patients without any past history of condyloma and those with less than 2 high-risk HPVs at baseline were more likely to heal.

Conclusion: Progression to invasive cancer is a rare event. Large, prospective cohort studies are needed to plan coherent strategies for both follow-up and treatment. 


\section{Introduction}

The incidences of anal cancer and its putative precursor (high-grade squamous intraepithelial lesions: HSIL) have greatly increased in recent decades $(1,2,3)$ particularly in special population subgroups: men who have sex with men (MSM), those infected with human immunodeficiency virus (HIV), and women with previous cervical human papillomavirus (HPV)-related disease (4).

Anal carcinoma increased from 0.2 to $0.5 / 100000$ person-years among men and from 0.7 to 1.3/100 000 person-years among women from 1982 to 2012. (3).

Regarding cervical cancer, it is widely recognized that HSIL and superficially invasive squamous cell carcinoma (SISCCA) can preclude invasive cancer. The latter is defined as a nearly stage tumours $\leq 10 \mathrm{~mm}$, corresponding to HSIL which has an invasive depth of $\leq 3 \mathrm{~mm}$ from the basement membrane of the point of origin, with horizontal spread of $\leq 7 \mathrm{~mm}$ at its maximal extent (5). Both types of lesions are induced by persistent infections of carcinogenic HPV (6, 7). Conventionally, they are likely to progress to an invasive cancer (5). Little is known about the natural history of anal HPV infections and HSIL. One study estimated a HSIL regression rate of $23.5 \%$ per year (8).

The lack of data about the natural progression of HSIL and SISCCA to invasive cancers has led to unclear and controversial therapeutic strategies. Management of HSIL varies according to the doctor's expertise, ranging from expectant management with close surveillance $(9,10)$ to surgical treatment (11), topical application of chemotherapeutic agents (12) or photodynamic therapy (13). To date, the recommended treatment for SISCCA is radiotherapy, but it has been 
associated with anatomical and functional side effects unless effective $(14,15,16)$. After we collected the data of consecutive patients with histologically proven HSIL, the aim of this study was to assess the clinical outcome with a special focus on the healing rate.

\section{Patients and Methods}

\section{Patients}

This cross-sectional study was conducted in a single tertiary gastroenterology unit (Rennes University Hospital, France) using the records of a central database. All patients with histories of HSIL (only AIN3 in the former classification) or SISCCA proven on anal biopsy, from March 2002 to May 2014, were invited to participate in a new evaluation. Medical records, using both retrospective (2002-2006) and prospective (2007-2014) databases, were extracted with special emphases on MSM and women with HPV-related genital lesions and HPV-related lesions, as well as smoking habits and immunosuppressant use. Data about life style and HIV disease were collected using a standardized questionnaire sent to the patient: gender, age, sexual activity, past history of sexually transmitted infections, and HIV status, including CDC stage, highly active antiretroviral therapy (HAART), CD4 cell count, and HIV viral load. Patients who did not respond to the questionnaire were solicited by phone and by sending new mail. To identify clinically relevant events that might interfere with clinical outcome, each treatment procedure was noted: surgery (specifying with or not healthy margins); destruction of the lesion (including electrocoagulation and infrared); or application of imiquimod. We also reported the periods of duration of therapies and the number of surgical events. 
Most of the patients were evaluated every 6 months to ensure the lack of progression. Any abnormalities were evaluated by high-resolution anoscopy (HRA) (performed using $5 \%$ acetic acid and Lugol's solution to magnify the visualization of abnormal anal tissue), and multiple targeted biopsies were performed (to limit heterogeneity and to ensure that the highest grade of dysplasia was identified). Random biopsies were also collected from regions that appeared normal at the level of the dental line. Finally, control biopsies of previous HSIL sites were realized at the end of the follow-up to determine whether the lesion persisted (HSIL), was down-staged (LSIL) or had healed (normal histology).

HPV DNA detection and genotyping

Before anoscopy, one Dacron swab was collected from the anal canal and was immediately suspended in Thin Prep PreservCyt medium (Hologic, Inc. Bedford, MA, USA). This sample was sent for virological analysis. Specimens were maintained at $+4^{\circ} \mathrm{C}$ before processing for analyses and then were aliquoted and stored at $-80^{\circ} \mathrm{C}$. DNA testing was performed using the PreservCyt medium: $200 \mu \mathrm{L}$ were used for DNA extraction on MagNA Pure LC (Roche, Bâle, Switzerland). Anal specimens were tested for 35 HPV genotypes with CLART Human Papillomavirus 2 (Genomica, Madrid, Spain), a commercial kit for the detection of 15 low risk $\operatorname{HPV}(6,11,40,42,43,44,54,61,62,71,72,81,83,84,89)$, and 20 high risk HPV strains (16, $18,26,31,33,35,39,45,51,52,53,56,58,59,66,68,70,73,82,85)$. The tests included a cellular control and an internal control. Microarray studies were analysed using a Clinical Arrays Reader (Genomica). A sample of $2 \mathrm{~mL}$ of each liquid-based medium was then frozen at $-80^{\circ} \mathrm{C}$. The Ahr-HPV DNA test was considered positive if at least one hr-HPV genotype was detected. 
Follow-up

The initial histology reporting HSIL or SISCCA was the first point of follow-up, and the last point was the most recent histology. Follow-up continued until June 30, 2014. Loss to followup was defined by the lack of response to any questionnaire or the inability to find the patient.

Most of the patients were evaluated every 6 months to ensure the lack of progression. Any abnormalities were biopsied. Regression was defined by Regression was defined by the stable regression of HSIL to a less invasive state (LSIL or normal) from the first change to the last biopsy of the follow-up. Regression had to be stable throughout the follow-up. In the regression group, we distinguished down-staged (LSIL) and healed (normal histology) states.

Progression was defined by the occurrence of SISCCA for patients with HSIL or invasive carcinoma for patient with SISCCA or HSIL.

The patients were separated into three groups according to their follow-up status: regression and/or healing; persistence of HSIL/SISSCA; or progression to invasive cancer.

Ethics

The database was authorized by the national regulatory institution, Commission Nationale Informatique et Liberté, and the study was approved by our institutional ethical committee (October 17, 2013: $n^{\circ} 13.59$ ). All of the responding participants provided written informed consent.

\section{Statistics}

Quantitative variables are described as the mean \pm standard deviation (SD). Categorical variables are presented as totals and percentages of the cohort. Wilcoxon's non-parametric 
signed-rank test for continuous variable and Pearson's non-parametric Pearson test for categorical variable were used to compare disease characteristics. Univariate analyses identified parameters associated with sustained healing. Effect of population studies do not allow for confident multivariate analysis. A p value $<0.05$ was considered significant. Finally, the cumulative probabilities of healing were estimated using the Kaplan-Meier method from the diagnosis of HSIL or SISCCA to the occurrence of healing. Statistical analyses were performed using JMP ${ }^{\circledR}$ Pro software, version 10.2,2013 (SAS Institute Inc., Cary, NC, USA).

\section{Results}

Population

From March 2002 to June 2014, 59 patients with HSIL or SISCCA on biopsy were referred to the Rennes University Hospital, France. We excluded 8 patients due to misdiagnoses: they had a true invasive anal squamous carcinoma at the time of initial diagnosis with a discrepancy between histological consideration and macroscopically ulcerative and infiltrative aspects. As a result, 51 patients with histologically confirmed HSIL or SISCCA were available for follow-up. Five patients (9.8\%) (4 patients with HSIL and one patient with SISCCA) did not have a control biopsy for several reasons (two lost to follow-up, two with follow-ups that were tot short, one due to unrelated death from ovarian cancer), leaving forty-six patients adequately followed (Figure 1). Self-perception of the follow-up strategy was assessed: 7 of 46 (15\%) did not respond to these items; 23 of 46 patients (50\%) judged it as compelling, 32 o 46 (70\%) were aware of the need for regular monitoring, and 33 of $46(72 \%)$ reported some anxiety with it. 
The main characteristics of the study population are summarized in Table 1 . The mean age was $48 \pm 2.1$ years old. In the cohort, all of the men with HIV infection were homosexual, except two and 4 HIV-negative who were homosexual. All except one were Caucasian.

Table 2 summarizes the symptoms, the physical evaluation and the first virology at referral. Twenty-five patients (49\%) were symptomatic on presentation. Macroscopic signs of HPV were observed in 34 patients (66.5\%), including external condyloma $(n=13)$ and/or endocanal lesions $(n=21)$, whereas 17 patients (33\%) had no abnormalities at clinical examination. DNA genotyping was not routinely performed before 2011; thus, 19 patients (37\%) had their first virology after their diagnosis of HSIL, whereas 25 (49\%) had their diagnoses the same time. For seven patients (14\%), virology was never performed.

Among 41 patients with HSIL, 6 were treated by excision, 13 by destruction, 2 by application of imiquimod, and 14 by combined treatment, and 6 received a conservative approach because no macroscopic lesion was observed. Among the 5 patients with SISCCA, 3 were treated by excision and two by combined treatment. None received radiotherapy to treat either HSIL or SISCCA.

Follow-up

The mean follow-up was 34.6 \pm 3.9 months. Among the patients with HSIL at inclusion, 14 (34\%) had persistent lesions of HSIL at the end of the study, 14 (34\%) regressed to LSIL after $18 \pm 4.1$ months, and $13(32 \%)$ healed after $22 \pm 3.8$ months. Among the patients with initial SISCCA, 2 (40\%) had persistent lesions of HSIL, 2 (40\%) healed after a mean follow-up of $51.5 \pm 0.5$ months, and one (20\%) progressed to an invasive cancer. The latter was surgically removed as a prior strategy. After an initial follow-up of 6 years showing no significant regression of persistent HSIL, he developed an invasive cancer of stage pT1NOM0, which was 
treated only by excision because he refused radiotherapy: he progressed 6 years later to a more severe cancer.

Another patient with initial HSIL progressed to SISCCA four years after the diagnosis and then regressed to HSIL after an excision.

Down-staging was finally observed in 29 patients (63\%), including 15 who healed (33\%). Thus, persistence of HSIL was found in 16 patients (35\%) at the end of follow-up.

Figure 2 illustrates the healing rate according to the length of follow-up. The cumulative probabilities of healing were $14 \%, 49 \%$ and $74 \%$ after follow-ups of 1,3 and 5 years, respectively.

Virology

The mean number of viruses and HR viruses were, respectively, $2.23 \pm 0.29$ and $1.74 \pm 0.23$ (HSIL: $2.3 \pm 0.3,1.8 \pm 0.25$ and SISCCA: $1.8 \pm 1.1,1.2 \pm 0.6)$ at the end of the follow-up. Between the baseline and final virology, the number of high-grade viruses decreased for twenty-one patients (46\%) (mean: $-1.8 \pm 0.25$ ), increased for four patients (9\%) (mean: $1.8 \pm 0.49$ ) and remained the same for eleven patients $(24 \%)$. Seven patients $(14 \%)$ had no virology at referral. For three patients (6.5\%), we did not found viruses either at baseline or at the end of follow-up, but virology was entirely realized after histology, so viral clearance could have occurred. Only two patients had complete viral clearance; one other patient eliminated highgrade viruses, but a low-grade virus persisted. Among the patients who healed (15 patients), the final virology found complete viral clearance only in 1 of $11(9 \%)$ when virology realized. The healed subjects had a significantly lower rate of viruses at baseline than the others (mean viruses: 1.58 vs $2.8, p=0.048$ ), and those who had at least two high-grade viruses at referral were less likely to regress ( $16.5 \%$ vs $44.5 \%, p=0.049)$. 
Factors associated with a better rate of healing

The main factors associated with sustained healing are reported in Table 3. At referral, patients with a better chance to heal were older, heterosexual, with no past history of condyloma and less than 2 identified high-risk HPVS. At the end of the follow-up, none of the 14 current smokers healed. HIV status, immunosuppression total number of sexual partners over one's life, HPV16 status, and a past history of anal sex were not significantly associated with a higher healing rate. Among patients with HIV, those infected for more than 10 years a greater likelihood to heal than the others ( $36 \%$ vs $0 \%, p=0.045$ ).

The type of therapeutic procedure (including imiquimod, destruction, excision, combined treatment or simple monitoring) was not significantly associated with a higher healing rate. Moreover, among the 6 patients who were untreated, all regressed, and 3 healed.

\section{Discussion}

This study, analysing the clinical outcome of anal dysplasia, was the first to define the factors and to quantify the healing of HSIL in a cohort of HIV-infected and uninfected-patients.

The data of the present study emphasize some aspects of the clinical outcome of HSIL.

HSIL is not only an HIV+ related disease. Our data emphasized that a large proportion of HSIL and SISCCA lesions were found in HIV-uninfected, heterosexual, immunocompetent patients (11 patients, 21.5\%) (including 4 active smokers, 2 with past histories of high-grade cervical 
dysplasia, and 1 who had undergone haemorrhoidectomy). Indeed, although immunosuppression has been clearly recognized as a risk factor for HSIL and anal carcinoma, only $8 \%$ of anal cancers occur in HIV patients $(17,18)$.

There have been no studies determining the population of patients with HSIL. All of the previous published series have been performed in selected high-risk groups: HIV-positive subjects, homosexual men or women with past histories of cervical HPV infection. In cervical dysplasia, only 5 to $8 \%$ of patients are HIV positive (19). An American cases series described penile intraepithelial neoplasia in 7 men, and only one was HIV positive, while the others were all immunocompetent (20).

These results suggested that anal dysplasia is not a condition that is only related to a patient's HIV patient's status, and it could also be found in immunocompetent, heterosexual patients.

Progression to invasive cancer is a rare event. We confirmed previous findings that progression of HSIL to anal cancer is uncommon $(9,10,11,21,22)$, and the expected rate of anal cancer for HSIL is lower than that for cancer of the cervix, where $31.3 \%$ and $50.3 \%$ of women with cervical intraepithelial neoplasia will progress to cervical cancer over time in the absence of treatment (23).

In our study, only one HIV patient progressed to an invasive cancer. We can, however, speculate that the length of the follow-up was probably too short to observe malignant transformation. This fact might limit the validity of our conclusions. Indeed, most of the published studies have reported median times of 3 to 6 years before progression to cancer $(10,11,22)$, which might be a rationale for shortening the interval of screening in selected groups. From a semantic point of view, SISCCA is defined as a nearly stage invasive cancer limited in depth of $\leq 3 \mathrm{~mm}$ from the basement membrane. By contrast, HSIL has no invasion 
across the basement membrane. For these reasons, one may speculate to exclude these cases from the present cohort study. But, this very rare condition is discussed in multidisciplinary staff and the therapeutic strategy is currently similar to HSIL. In other words, simple surgical RO excision is preferred over radiotherapy or radiochemotherapy. By contrast to HSIL, SISCCA has a limited area of involvement among larger HSIL surface. After excision, HSIL may persist after removal of the SISCCA target.

Spontaneous regression and healing can occur. Two-thirds of HSIL lesions in the present study regressed, and half of them healed within a 3-year period of time. These results were in agreement with a previous study that reported a rate of $37.1 \%$ per year of spontaneous regression in HIV-uninfected patients, but the regression rate was lower in subjects with HIV (19.2\% per year) (8). Mechanisms leading to healing remain however unclear. Viral clearance does not explain healing by itself (only one patient who was cured had complete viral clearance), and cofactors could be implicated, such the level of co-infections, because most of the patients who were cured had fewer viruses than at baseline.

We can speculate that healing might precede clearance of oncogenic HPV infection. These results were previously described by Schiffman et al, who found that cytologic abnormalities regressed 77 days before HPV DNA (23).The authors compared cytologic abnormalities to "tip of the iceberg" HPV infections, and they occurred in the middle of the natural history of some, whereas HPV DNA detection lasted longer. Moreover, in epidemiologic studies, HPV DNA detection precedes and predicts subsequent cytologic and histologic abnormalities (24).

Other mechanisms could explain HSIL healing. The impact of genetic factors on the regression of high-grade cervical dysplasia was already suggested by Trimble et al (25). Women expressing HLA*A201 and infected with a high-risk virus were three time more likely to 
regress than others. To date, no authors have studied the susceptibility of genetic factors in high-grade dysplasia healing or regression.

Several factors might be associated with a higher healing rate. Our findings emphasized the importance of smoking, as well as sexually active lifestyles, homosexual sex, HPV high-risk genotyping, and a past history of condyloma as predictive factors for lack of healing. Interestingly, older patients appeared to have a better healing rate, thus contrasting previous reports (8). Confounding variables could explain these discrepancies, such as the number of sexual partners, an active sexual life and current exposure to tobacco.

In our study, HIV status was not associated with a lower healing rate. Most studies report that Highly active antiretroviral therapy (HAART) does not increase the probability of regression, (26). One hypothesis is that our cohort was not powered to assess an association between HIV and healing: both the population size and follow-up were insufficient to draw conclusions.

Treatment strategies have been somewhat disappointing. Our results emphasized that treatments (excision, destruction, imiquimod) did not impact the healing rate. Moreover, among the 6 HIV patients who were only assessed (no visible lesions so no treatment), all of them regressed, and three healed. These data led us to believe that, in most cases, HSIL lesions regress regardless of the care realized. Although no prospective randomized trials have been performed on the expectant management of $\mathrm{HSIL}$, some retrospective studies have supported our hypothesis: Tong et al found a spontaneous HSIL regression rate of $23.8 \%$ per year (8), but in other reports, treatment has been needed to avoid progression $(27,28)$. In the present study, varied treatments have been applied to different conditions (visible and non visible lesions). Thus, this small cohort does not allow concluding a preferred strategy. In 
another hand, treatment did not better cure as compared to simple observation. Moreover, the present cohort has probably a too short follow-up to point the rare events of progression to invasive cancer. Finally, the main message is a long standing state of HSIL and the negative statistical link of tobacco on healing. Larger and prospective randomized studies are expected to standardize the strategy to adopt, including close surveillance for patients who are likely to regress. Local treatment might be reserved for patients at risk to progress and or cases of SISCCA with macroscopic targets to treat. This hypothesis could be tested in prospective, multicentre and interventional studies.

The strengths of our study include our robust histology-based definition of HSIL, whereas most of studies have defined progression and regression using cytology. In fact, compared to cervical cytology, anal cytology is significantly less sensitive and specific for detecting highgrade disease (29). Moreover, we avoided selection bias by not including AIN2 lesions: indeed, we know that AIN2 lesions can be prone to confusion between high and low grade lesions. Our choice of subjects, including men, women, HIV-infected and uninfected patients, men who have sex with men and heterosexual people, made our study population very close to real life, rather than a very selected group of subjects who are MSM.

Our study, however, had a number of potential limitations. Some of the data were retrospective, the follow-up was quite short, and our cohort had a relatively small number of patients, which prevented us from realizing multivariate analysis. Moreover, although HRA remains the standard for the detection of anal dysplasia, it is by no means perfect, and lesions might not have been detected, leading to an underestimation of recurrence rates. Finally, the heterogeneity of the received treatment (with small numbers in each group) is also a limit. 
In summary, our study made some important and innovative points. First, it was the first study to quantify the healing rate and associated healing factors of HSIL lesions. Second, we demonstrated that HSIL lesions were also found in immunocompetent patients and were not only an HIV-related disease. Third, healing occurred in most cases, likely regardless of the received treatment. Finally, the absence of viral clearance to explain healing was also a very important message, compelling us to search for other mechanisms involved in HSIL healing.

\section{Conclusion}

Progression to cancer was a rare event after a three-year follow-up. Clinical regression and healing occurred far more commonly in the clinical outcome of HSIL. This finding suggested that patients might not require treatment in the initial phase of the diagnosis. Tobacco, sexually active lifestyles, homosexual sex, a number of high risk viruses at baseline and a past history of condyloma seemed to be predictive factors for more difficult healing. Future largerscale studies are necessary to plan coherent surveillance and treatment strategies and to stratify patients according to their progression risks. 
Titles of tables and figures.

Table 1: Characteristics of the study group ( $\mathrm{N}=51)$

Table 2: Complaints and examinations at referral $(\mathrm{N}=51)$

Table 3: Factors associated with sustained healing $(\mathrm{N}=46)$

Figure 1: Flow chart of the cohort

Figure 2: Healing rate 


\section{References}

1. Johnson LG, Madeleine MM, Newcomer LM, Schwartz SM, Daling JR. Anal cancer incidence and survival: the surveillance, epidemiology, and end results experience, 19732000. Cancer. 2004;101:281-8.

2. Nelson RA, Levine AM, Bernstein L, Smith DD, Lai LL. Changing patterns of anal canal carcinoma in the United States. J Clin Oncol. 2013;31:1569-75.

3. Bouvier AM, Belot A, Manfredi S, Jooste V, Uhry Z, Faivre J et al. Trends of incidence and survival in squamous-cell carcinoma of the anal canal in France: a population-based study. Eur J Cancer Prev. 2015 May 11.

4. Edgren G, Sparén P. Risk of anogenital cancer after diagnosis of cervical intraepithelial neoplasia: a prospective population-based study. Lancet Oncol. 2007;8:311-6.

5. Darragh TM, Colgan TJ, Thomas Cox J, Heller DS, Henry MR, Luff RD et al. The Lower Anogenital Squamous Terminology Standardization project for HPV-associated lesions: background consensus recommendations from the College of American Pathologists and the American Society for Colposcopy and Cervical Pathology. Int J GynecolPathol2013;32:76-115.

6. McCance DJ, Clarkson PK, Dyson JL, Walker PG, Singer A. Human papillomavirus types 6 and 16 in multifocal intraepithelial neoplasias of the female lower genital tract. $\mathrm{Br} \mathrm{J}$ ObstetGynaecol. 1985; 92:1093-100.

7. Palmer JG, Scholefield JH, Coates PJ, Shepherd NA, Jass JR, Crawford LV et al. Anal cancer and human papillomaviruses. Dis Colon Rectum. 1989;32:1016-22.

8. Tong WW, Jin F, McHugh LC, Maher T, Sinclair B, Grulich AE, Grulich AE et al. Progression to and spontaneous regression of high-grade anal squamous intraepithealial lesions in HIV-infected and uninfected men. AIDS. 2013;27:2233-43.

9. Chang GJ, Berry JM, Jay N, Palefsky JM, Welton ML. Surgical treatment of high-grade anal squamous intraepithelial lesions: a prospective study. Dis Colon Rectum. 2002;45: 453-8.

10. Scholefield JH, Castle MT, Watson NF. Malignant transformation of high grade anal intraepithelial neoplasia.Br J Surg. 2005;92:1133-6.

11. Scholefield JH, Ogunbiyi OA, Smith JH, Rogers K, Sharp F. Treatment of anal intraepithelial neoplasia. Br J Surg. 1994;81:1238-40.

12. Wieland U, Brockmeyer NH, Weissenborn SJ, Hochdorfer B, Stücker M, Swoboda J et al. Imiquimod treatment of anal intraepithelial neoplasia in HIV-positive men. Arch Dermatol. 2006;142:1438-44.

13. Webber J, Fromm D. Photodynamic therapy for carcinoma in situ of the anus. Arch Surg. 2004;139:259-61.

14. Ortholan C, Ramaioli A, Peiffert D, Lusinchi A, Romestaing P, Chauveinc L et al. Anal canal carcinoma: early stage tumors $<$ or $=10 \mathrm{~mm}$ (T1 or Tis): therapeutic options and original pattern of local failure after radiotherapy. Int J RadiatOncolBiolPhys 2005;62:479-85. 
15. R. Glynne-Jones1, P. J. Nilsson2, C. Aschele3, V. Goh4, D. Peiffert5, A. Cervantes et al. Anal cancer: ESMO-ESSO-ESTRO Clinical Practice Guidelines for diagnosis, treatment and follow-up. Annals of Oncology 25 (Supplement 3): iii10-iii20, 2014.

16. Benson AB 3rd, Arnoletti JP, Bekaii-Saab T, Chan E, Chen YJ, Choti MA et al. Anal Carcinoma, Version 2.2012: featured updates to the NCCN guidelines. J Natl Compr Canc Netw. 2012;10:449-54.

17. Piketty C, Selinger-Leneman H, Bouvier AM, Belot A, Mary-Krause M, Duvivier C et al. Incidence of HIV-related anal cancer remains increased despite long-term combined antiretroviral treatment: results from the french hospital database on HIV. J

ClinOncol. 2012;30:4360-6.

18. French Hospital Database on HIV. (http://www.ccde.fr).

19. Moodley JR, Hoffman M, Carrara H, Allan BR, Cooper DD, Rosenberg L et al. HIV and preneoplastic and neoplastic lesions of the cervix in South Africa: a case-control study. BMC Cancer 2006;6:135

20. Zhou J, Howard M, Williams D, Richardson D. Penile intraepithelial neopl neoplasia: important lessons from a case series. Int J STD AIDS 2013;24:585-6.

21. Hemminki K, Dong C, Vaittinen P. Second primary cancer after in situ and invasive cervical cancer. Epidemiology. 2000;11:457-61.

22. Watson AJ, Smith BB, Whitehead MR, Sykes PH, Frizelle FA. Malignant progression of anal intra-epithealial neoplasia.ANZ J Surg. 2006;76:715-7.

23. Schiffman M, Wheeler CM, Castle PE; Atypical Squamous Cells of Undetermined Significance/Low-Grade Squamous Intraepithelial Lesion Triage Study Group. Human papillomavirus DNA remains detectable longer than related cervical cytologicabnormalities. J Infect Dis. 2002;186:1169-72.

24. Moscicki AB, Hills N, Shiboski S, Powell K, Jay N, Hanson E et al. Risks for incident human papillomavirus infection and low-grade squamous intraepithelial lesion development in young females. JAMA 2001;285:2995-3002.

25. Trimble CL, Piantadosi S, Gravitt P, Ronnett B, Pizer E, Elko A et al. Spontaneous regression of high-grade cervical dysplasia: effects of human papillomavirus type and HLA phenotype.Clin Cancer Res. 2005;11:4717-23.

26. Moscicki AB, Shiboski S, Hills NK, Powell KJ, Jay N, Hanson EN et al. Regression of lowgrade squamous intra-epithelial lesions in young women. Lancet. 2004; 364:1678-83.

27. Goldstone RN, Goldstone AB, Russ J, Goldstone SE. Long term follow-up of infrared coagulator ablation of anal high grade dysplasia in men who have sex with men. Dis Colon Rectum. 2011;54:1284-92.

28. Goldstone SE, Johnstone AA, Moshier EL. Long-term outcome of ablation of anal highgrade squamous intraepithelial lesions: recurrence and incidence of cancer. Dis Colon Rectum 2014;57:316-23.

29. Cachay ER, Agmas W, Mathews WC. Relative accuracy of cervical and anal cytology for detection of high grade lesions by colposcope guided biopsy: a cut-point meta-analytic comparison. PLoS One. 2012;7:e3895. 
Table 1. Characteristics of the study group $(\mathrm{N}=51)$

\begin{tabular}{|c|c|c|c|}
\hline & & $\mathbf{N}$ & $\%$ \\
\hline \multirow[t]{2}{*}{ Sex } & Male & 37 & 73 \\
\hline & Female & 14 & 27 \\
\hline \multicolumn{2}{|l|}{ Age (years, mean) } & $48 \pm 2.1$ & \\
\hline \multicolumn{2}{|l|}{ BMI (mean) } & $24 \pm 1.2$ & 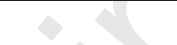 \\
\hline \multirow[t]{2}{*}{ Past history of STI not related to HPV } & Yes & 18 & 35 \\
\hline & No & 33 & 65 \\
\hline \multirow[t]{2}{*}{ Past history of condyloma/HPV infection } & Yes & 24 & 47 \\
\hline & No & 27 & 53 \\
\hline \multirow{2}{*}{$\begin{array}{l}\text { Past history of cervical cancer or } \\
\text { conization }\end{array}$} & Yes & 05 & 36 \\
\hline & No & 09 & 64 \\
\hline \multirow[t]{2}{*}{ Past history of LSIL } & Yes & 07 & 14 \\
\hline & No & 44 & 86 \\
\hline \multirow[t]{2}{*}{ HIV } & Yes & 33 & 65 \\
\hline & No & 18 & 35 \\
\hline \multirow[t]{2}{*}{ MSM } & Yes & 32 & 86 \\
\hline & No & 5 & 14 \\
\hline \multirow[t]{2}{*}{ Immune-suppression treatment * } & Yes & 03 & 6 \\
\hline & No & 48 & 94 \\
\hline \multirow[t]{3}{*}{ Smoking } & Current and/or & 25 & 49 \\
\hline & past & 26 & 51 \\
\hline & Never & & \\
\hline \multirow[t]{3}{*}{ Past history of anal sex } & Yes & 37 & 72.5 \\
\hline & No & 12 & 23.5 \\
\hline & Unknown & 2 & 4 \\
\hline \multirow{5}{*}{ Total number of sexual partners } & $<5$ & 4 & 7.5 \\
\hline & {$[5-10[$} & 9 & 17.5 \\
\hline & {$[10-50[$} & 14 & 27.5 \\
\hline & $>50$ & 18 & 35.5 \\
\hline & Unknown & 6 & 12 \\
\hline \multirow[t]{3}{*}{ Sexually active life } & Yes & 30 & 59 \\
\hline & No & 19 & 37 \\
\hline & Unknown & 2 & 4 \\
\hline \multicolumn{4}{|c|}{ * One Horton disease and two renal transplantations } \\
\hline \multicolumn{4}{|c|}{$\begin{array}{l}\text { Abbreviations: BMI: Body Mass Index, HAART: Highly Active Antiretroviral Therapy, HIV: } \\
\text { Human Immunodeficiency Virus, HPV: Human Papillomavirus, LSIL: Low grade Superficial } \\
\text { Intra-epithelial Lesion, MSM: Men who have Sex with Men, STI: Sexually Transmissible } \\
\text { Infection. }\end{array}$} \\
\hline
\end{tabular}


Table 2. Complaints and examinations at referral $(\mathrm{N}=51)$

\begin{tabular}{|c|c|c|c|c|}
\hline & & HSIL & SISCCA & Total \\
\hline & & $\mathrm{N}=45$ & $\mathrm{~N}=6$ & $N=51$ \\
\hline \multirow[t]{6}{*}{ Symptoms } & Pain & $4(9 \%)$ & 0 & $4(8 \%)$ \\
\hline & Rectal bleeding & $8(18 \%)$ & $2(33.5 \%)$ & $10(20 \%)$ \\
\hline & Soiling & $5(11 \%)$ & $1(17 \%)$ & $6(12 \%)$ \\
\hline & Palpable lesion & $4(9 \%)$ & 0 & $4(8 \%)$ \\
\hline & Pruritus & 0 & $1(17 \%)$ & $1(2 \%)$ \\
\hline & No abnormalities & $24(53.5 \%)$ & $2(33.5 \%)$ & $26(50.5 \%)$ \\
\hline \multirow[t]{7}{*}{ Examination } & Flat suspicious lesion & $13(29 \%)$ & $3(50 \%)$ & $16(31.5 \%)$ \\
\hline & Induration & 0 & $1(17 \%)$ & $1(2 \%)$ \\
\hline & Anal fissure & $1(2 \%)$ & $1(17 \%)$ & $2(4 \%)$ \\
\hline & Condyloma & $13(29 \%)$ & 0 & $13(25.5 \%)$ \\
\hline & Ulceration & $1(2 \%)$ & 0 & $1(2 \%)$ \\
\hline & Polypoid lesion & $1(2 \%)$ & 0 & $1(2 \%)$ \\
\hline & No abnormalities & $16(35.5 \%)$ & $1(17 \%)$ & $17(33 \%)$ \\
\hline \multirow[t]{7}{*}{ First virology* } & & & & \\
\hline & Number of viruses (mean) & $3.45 \pm 0.37$ & $1.5 \pm 1.19$ & $3.26 \pm 0.36$ \\
\hline & Number of HR HPV (mean) & $2.61 \pm 0.3$ & $0.7 \pm 0.5$ & $2.45 \pm 0.29$ \\
\hline & HPV 16 & 20 (44.4\%) & 2 (33.5\%) & 22 (43\%) \\
\hline & HPV 18 & $1(2 \%)$ & 0 & $1(2 \%)$ \\
\hline & No virus & $1(2 \%)$ & $2(33.5 \%)$ & $3(6 \%)$ \\
\hline & Not realized & 6 (13.5\%) & $1(17 \%)$ & $7(14 \%)$ \\
\hline \multicolumn{5}{|c|}{$\begin{array}{l}\text { Abbreviations: HSIL: High-grade squamous intraepithelial lesions, SISCCA: Superficially invasive squamous cel } \\
\text { carcinoma, LSIL: Low grade superficial intra-epithelial lesion, ASCUS: Atypical squamous cells of undeterminec } \\
\text { significance, HPV: Human papillomavirus, HR: High risk } \\
\text { *realized at the same time as the first histology or after }\end{array}$} \\
\hline
\end{tabular}


Table 3. Factors associated with a sustained healing $(N=46)$

\begin{tabular}{|c|c|c|}
\hline & Sustained healing ( $N, \%)$ & p \\
\hline Past history of condyloma ( $\mathrm{N}=46$ ) & & 0.009 \\
\hline Yes & $4(16 \%)$ & \\
\hline No & $11(52 \%)$ & \\
\hline Age $(N=46)$ & & 0.007 \\
\hline$<44$ years & $2(10.5 \%)$ & \\
\hline$\geq 44$ years & $13(48 \%)$ & \\
\hline Active sexual life $(N=46)$ & & 0.045 \\
\hline Yes & $6(21.5 \%)$ & \\
\hline No & $9(50 \%)$ & \\
\hline MSM* (N=35) & & 0.011 \\
\hline Yes & $7(23 \%)$ & \\
\hline No & $4(80 \%)$ & \\
\hline Active smoking $(\mathrm{N}=46)$ & & 0.002 \\
\hline Yes & $0(0 \%)$ & \\
\hline 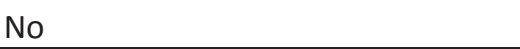 & $15(47 \%)$ & \\
\hline $\begin{array}{l}\geq 2 \text { high-grade virus at baseline** } \\
(N=39)\end{array}$ & $4(16.5 \%)$ & 0.049 \\
\hline 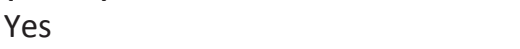 & $8(44.5 \%)$ & \\
\hline 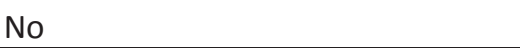 & & \\
\hline Past history of anal sex $(\mathrm{N}=46)$ & & 0.135 \\
\hline Yes & $9(26,5 \%)$ & \\
\hline No & $6(50 \%)$ & \\
\hline HIV (N=46) & $\sqrt{9}$ & 0.240 \\
\hline Yes & $8(27 \%)$ & \\
\hline No & $7(44 \%)$ & \\
\hline HPV 16 or 18 at baseline ${ }^{* *}(\mathrm{~N}=39)$ & & 0.845 \\
\hline Yes & $6(28 \%)$ & \\
\hline$+\sqrt{2}$ & $6(30 \%)$ & \\
\hline \multicolumn{3}{|c|}{$\begin{array}{l}\text { Abbreviations: MSM: Men who have sex with men } \\
* \text { analysis including only men } \\
* * \text { analysis including patients with a realized virology at baseline }\end{array}$} \\
\hline
\end{tabular}


Figure 1. Flow chart

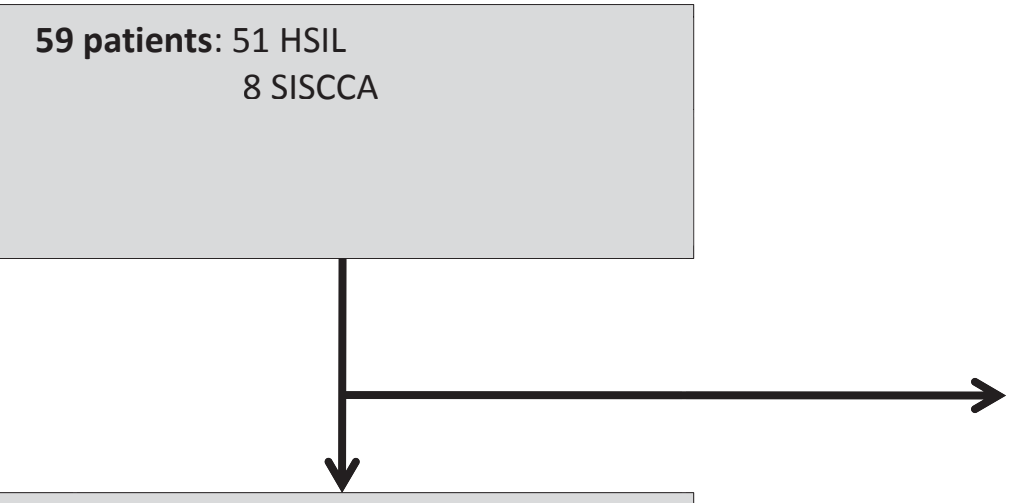

8 false HSIL: invasive anal carcinoma

51 patients: $45 \mathrm{HSIL}$

6 SISCCA

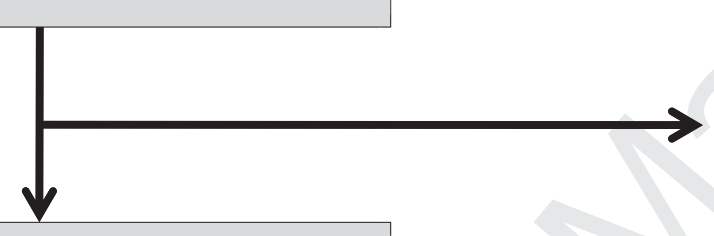

5 patients with inadequate follow-up:

2 lost to follow-up, 2 follow-up too

short, one death due to ovarian cancer

46 patients: $41 \mathrm{HSIL}$

5 SISCCA 
Figure 2. Healing rate

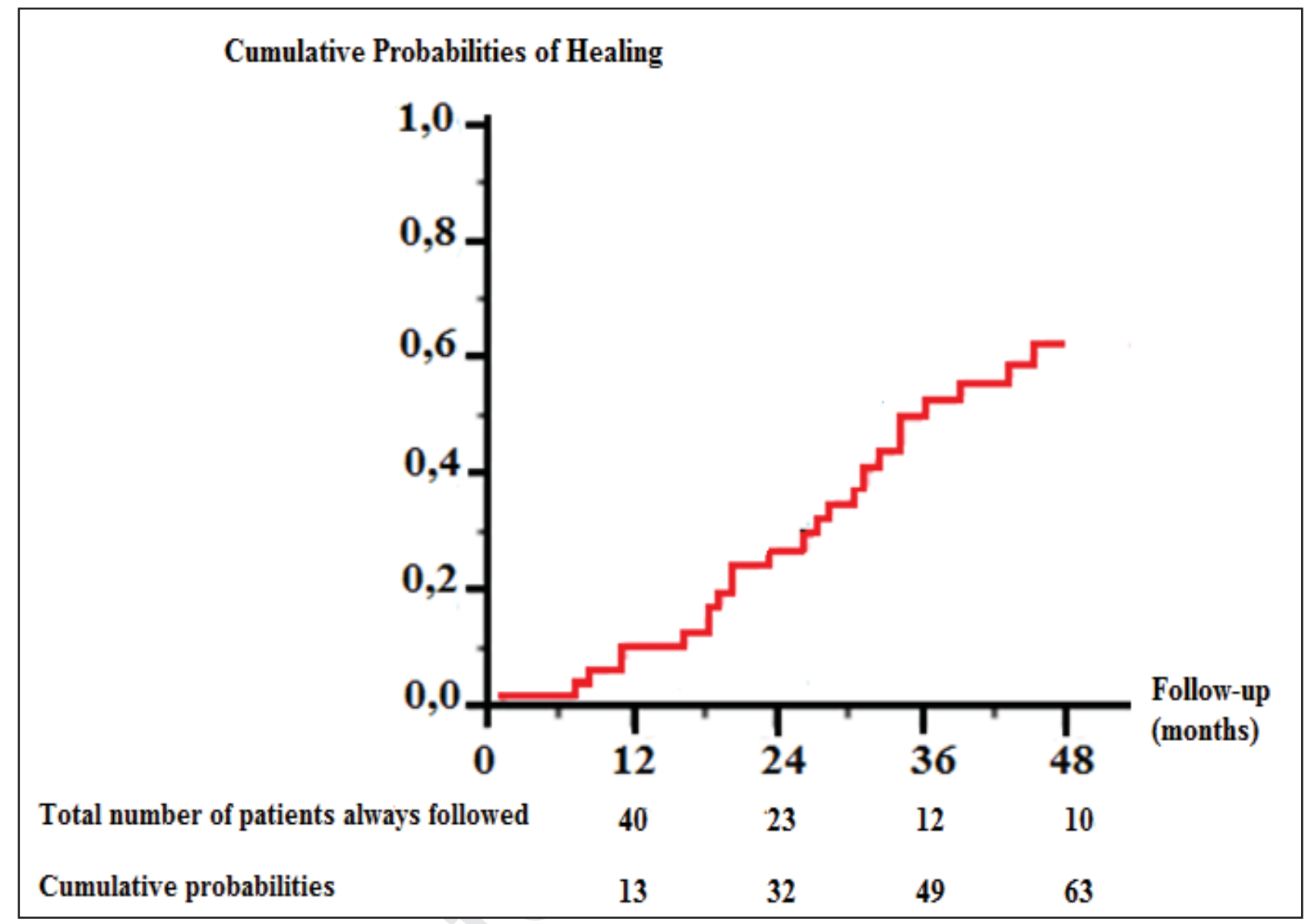

